$\xi=$

\title{
Alternate assessment of strength characteristics of clayey soil for compaction using ultrasonic pulse velocity method
}

\author{
Vinay. ${ }^{1 *}$, Dr. A. V. Pradeepkumar ${ }^{2}$, Dr. M. R Rajashekhara ${ }^{3}$ \\ ${ }^{1}$ Assistant Professor, Department of Civil Engineering, D.S.C.E, Bangalore, Karnataka, India \\ ${ }^{2}$ Superannuated Professor and Head, Department of Civil Engineering, J.N.N.C.E, Shimoga, Karnataka, India \\ ${ }^{3}$ Professors, Department of Civil Engineering, D.S.C.E, Bangalore, Karnataka, India \\ *Corresponding author E-mail: vinay.a.9333@gmail.com
}

\begin{abstract}
Earthwork is a component in any Civil Engineering construction and to determination of soil properties in the laboratory is the basis of design. Clayey soils exhibits large volume changes in presence of water leads to swelling and shrinkage. Soils used for construction should satisfy two important properties like less settlement and more shear strength. Present investigation deals with the determination of compaction characteristics of clayey soil by an alternate method of assessment like pulse velocity method which is more accurate and fast compared to conventional methods. Laboratory compaction soil samples prepared at different water content by standard and modified proctor, compaction method was used to determine the ultrasonic pulse velocity at different water contents. The variation of velocity with respect to water content was correlated. Ultrasonic pulse transmitted from one side of the sample was received at the other end and was used in calculating soil properties. It was observed that with increase in water content the density increases and ultrasonic pulse velocity also increases. Standard proctor method of compaction and modified proctor moulds was used for compaction and 5 trails were done with variation in water content to get compaction curve, so as to find the variation of strength to stabilization and its variation by Ultrasonic pulse velocity technique.
\end{abstract}

Keywords: Embankment Construction; Shear Strength; Transmission; Ultrasonic Pulse Velocity; Water Content.

\section{Introduction}

Clayey soils expedite very high volume change in the presence of water. Stabilization of clay soil is possible by different methods like lime, cement, fly ash, GGBS, etc. The strength assessment of soil may be made by different techniques like Unconfined Compression Strength and Tri-axial Test which is direct method. Apart from this indirect method like Ultrasonic Pulse Velocity method is also available which requires less time and it a Non-destructive testing method. In the present study clay soil is stabilized using lime with varying proportions and velocity of the Ultrasound wave through the specimen was studied. It was found that the velocity increases with strength of clayey soils. [10], [11].

\section{Research methodology}

The clay soil samples were obtained from Shivamogga district, Karnataka. The collection of clay soil samples was done by excavating soil at the site, at the depth of about 1.5 meters from original ground level. The obtained soil samples were pulverized using rammer to break the lumps and the samples were dried in air. The commercially available lime samples were obtained. The obtained lime samples were in the form of powder. Clay soils were used in conduction of laboratory tests to find out the properties like specific gravity and atterberg limits as per BIS 1377 Part-2 and results are tabulated in Table - 1 . The air dried clay soil samples and the percentage of lime by soil weight were mixed thoroughly for stabilization. The percentage of lime contents was varied from 5, 10 and 15 percent to weight of soil for stabilization process in the Laboratory.

\begin{tabular}{|c|c|c|c|c|c|}
\hline $\begin{array}{l}\text { Soil } \\
\text { No. }\end{array}$ & $\begin{array}{l}\text { Soil + } \\
\text { Lime }\end{array}$ & $\begin{array}{l}\text { Specific } \\
\text { Gravity }\end{array}$ & $\begin{array}{l}\text { Liquid } \\
\text { Limit } \\
\text { (Wl) \% }\end{array}$ & $\begin{array}{l}\text { Plastic } \\
\text { Limit } \\
\text { (Wp) \% }\end{array}$ & $\begin{array}{l}\text { Plastic } \\
\text { Index } \\
\text { (Ip )\% }\end{array}$ \\
\hline 1 & $\begin{array}{l}100+ \\
0\end{array}$ & 2.60 & 59 & 27 & 32 \\
\hline 2 & $95+5$ & 2.49 & 49 & 25 & 24 \\
\hline 3 & $\begin{array}{l}90+ \\
10\end{array}$ & 2.40 & 44 & 22 & 22 \\
\hline 4 & $\begin{array}{l}85+ \\
15\end{array}$ & 2.24 & 39 & 21 & 18 \\
\hline
\end{tabular}

In the present investigation Direct or Through transmission technique was used by placing one transmission at one end and receiver at the other end opposite to each other of the P - wave velocity was obtained as the ratio of travel time through the specimen length . The objective of the research is to evaluate the physical properties clayey soil and stabilization of clay soil by lime. Ultrasonic testing method is used as alternative to conventional On-site testing method to evaluate the impacts of lime stabilization on the strength.

The process of stabilizing the clay soil with lime for the evaluation of compaction characteristics by the means of ultrasonic measures (nondestructive method) are discussed in this part. The focus of the study was to identify the salient parameters that influence the mixing proportion and the properties of clay soil and lime stabilized soil. 


\section{Scope of research}

For conventional quality control in the field, the methods require samples to taken from the pavement by core cutting and subjecting them to further laboratory tests. This procedure is too slow, costly and provides information useful only for the official records and not for rectification of Detects during laying and compacting soil sub grade in the field. Fast on the spot measurements are therefore needed for the control of quality of the soil sub grade of pavement layer. These have lead to the development of Ultrasonic Pulse Velocity Method.

\section{Experimental details}

Stabilization was carried on clay soil using lime powder at different percentages for fixed numbers of curing days. Then experiment was conducted to know the strength character of clay specimens using Ultrasonic Pulse Velocity method. The complete details of experimentation details are given in the paragraphs.

\subsection{Clay soil}

Generally clay soils are black or grey in colour. The black colour is because of the presence of low concentration of titanium oxide. Clay soil is made up of mineral known as montmorillonite. This makes clay soil swell in saturation conditions and when water content expelled, shrinkage occurs in the soil. Hence it is important to study the discrepancy in the behavior of Clay soil.

\subsection{Lime powder}

Lime is a natural stabilizer being used from a long time in stabilization of weak soils in construction sites of all types. Lime stabilization increases stability of compacted soil, impermeability and bearing capacity of soil. In the present study quick lime is used for experimentation.

The soil lime interaction that results in Base Exchange or Ion Exchange is the main reason in attainment of requisite result. [12]

\subsection{Ultrasonic pulse velocity test}

Velocity of P-waves in compacted soil mass is determined by the ultrasonic test carried out using direct or through-transmission technique. The transducer arrangements for direct transmission techniques are shown in Figure 1.

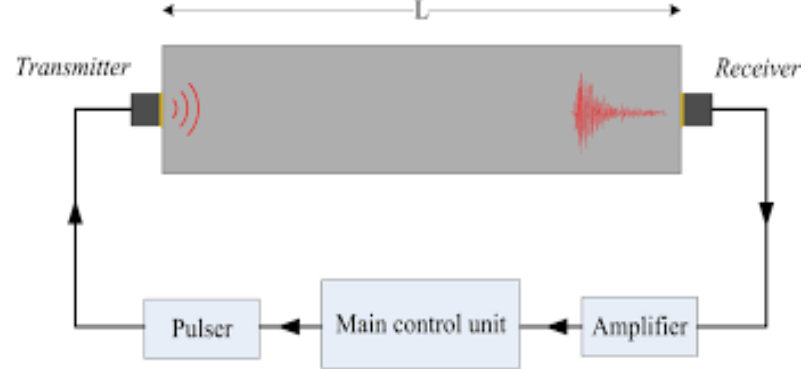

Fig. 1: Through or Direct Transmission Method for Soil Specimen.

Through Transmission Technique: This technique also referred as direct transmission. The transducers in direct transmission are placed on the opposite surfaces of the soil material. P-waves transmitted from the transmitting transducer are received on the receiving transducer at opposite plane of soil samples.

$\mathrm{P}$-wave velocity is obtained as the ratio of the travel path to the travel time of the waves. The thickness of the soil material is considered as the travel path of the transmitted waves.

The travel time of waves in through transmission techniques is obtained as first arrival time at receiving transducer. Earliest arrival time is defined as the distinction in the time of wave transmission by transmitting transducer and arrival time at receiver transducer. The digital data board is synchronized with pulse receiver such that the collection of data starts with the transmission of $p$ waves. Alongside the travel time of waves the speed at which the waves touches base at recipient from the transmitter along the compacted soil is recorded. The recorded data are valuable in examination of the adjustment in speed because of the compaction conditions and soil properties. [13]

Correlations between the compaction plots got with ultrasonic estimations (velocity v/s water content) were made. The soil stabilized with lime content $5 \%, 10 \%$ and $15 \%$ is compacted with varying water content using both standard and modified proctor effort. Comparisons among both standard and modified proctor were also made. The compacted soil mass is subjected to the ultrasonic pulse velocity test. The compacted soil mass were used in determination of p-wave velocity. The velocity obtained from the transmission tests were used in determination of compaction characteristics of the soil. The plots of dry density and velocity with relating moisture content were plotted.

\section{Data acquisition}

The present investigation it is intended to determine the ultrasonic pulse velocity through the soil stabilization using lime and the variation of velocity with difference percentages of lime. The time of travel of the wave was displayed on the digital broad and was converted to velocity of wave.

Table 5.1: Results of Light Compaction on Lime Stabilized Clay Soil

\begin{tabular}{|c|c|c|c|c|c|c|}
\hline CLAY SOIL AND LIME & WC \% & DRY DENSITY $\mathrm{kN} / \mathrm{m}^{3}$ & VELOCITY m/s & TIME $\mu$ sec & $\mathrm{T} 1$ & T 2 \\
\hline \multirow{4}{*}{ Clay $+5 \%$ LIME } & 16 & 12.62 & 933 & 160.7 & 7.7 & 7.8 \\
\hline & 18 & 12.69 & 934 & 160.5 & 8.2 & 8.2 \\
\hline & 20 & 12.78 & 1020 & 151.4 & 8.7 & 9.1 \\
\hline & 24 & 12.43 & 0 & 0 & 8.4 & 8.5 \\
\hline \multirow{5}{*}{ Clay + 10\% LIME } & 16 & 12.41 & 714 & 209.8 & 11.1 & 11 \\
\hline & 18 & 12.56 & 859 & 174.6 & 7.8 & 7.6 \\
\hline & 20 & 12.68 & 910 & 164.7 & 7.3 & 7.4 \\
\hline & 22 & 12.72 & 982 & 162.8 & 7.7 & 7.5 \\
\hline & 24 & 12.28 & 0 & 0 & 6.6 & 6.5 \\
\hline \multirow{5}{*}{ Clay $+15 \%$ LIME } & 16 & 12.3 & 595 & 202 & 9.8 & 10.1 \\
\hline & 18 & 12.36 & 815 & 184 & 10 & 9.7 \\
\hline & 20 & 12.43 & 847 & 177 & 7.6 & 7.8 \\
\hline & 22 & 12.47 & 900 & 185 & 8.3 & 8.2 \\
\hline & 24 & 12.18 & 0 & 0 & 5.9 & 5.7 \\
\hline
\end{tabular}


Table 5.2: Results of Heavy Compaction on Lime Stabilized Clay Soil

\begin{tabular}{|c|c|c|c|c|c|c|}
\hline CLAY SOIL AND LIME & WC \% & $\begin{array}{l}\text { DRY DENSITY } \\
\mathrm{kN} / \mathrm{m} 3\end{array}$ & VELOCITY m/s & TIME $\mu$ sec & T 1 & $\mathrm{~T} 2$ \\
\hline \multirow{4}{*}{ Clay $+5 \%$ LIME } & 8 & 17.41 & 644 & 265.3 & 157 & 157.1 \\
\hline & 10 & 17.44 & 870 & 195.7 & 130.1 & 130.2 \\
\hline & 12 & 17.46 & 1023 & 153.9 & 133.2 & 133.1 \\
\hline & 14 & 17.05 & 0 & 0 & 128.4 & 127.9 \\
\hline \multirow{3}{*}{ Clay $+10 \%$ LIME } & 8 & 17.23 & 614 & 256.4 & 245.9 & 245.7 \\
\hline & 10 & 17.25 & 835 & 188.5 & 83.2 & 83.7 \\
\hline & 12 & 17.28 & 987 & 159.5 & 112.3 & 113 \\
\hline \multirow{4}{*}{ Clay + 15\% LIME } & 8 & 16.68 & 637 & 247.1 & 113.4 & 112.9 \\
\hline & 10 & 16.83 & 919 & 171.3 & 124.7 & 125.1 \\
\hline & 12 & 16.85 & 983 & 160.1 & 122.3 & 122.5 \\
\hline & 14 & 16.52 & 0 & 0 & 131.8 & 132.4 \\
\hline
\end{tabular}

\section{Analysis of data}

The experimental results for the following testes are presented and discussed in this chapter. Following are results and discussions of the tests conducted for clay soil with different percentage of lime content by using ultrasonic testing measures.

The effect on the various properties of the soil with the influence of lime at different percentages are obtained by evaluation and generating the relation between various parameters of stabilized soil.

The parameters considered for the investigation are:

1) Velocity v/s Water content

2) Time v/s Water content

3) Velocity v/s Density

4) Time v/s Density

\subsection{For light compaction on lime stabilized clay soil}

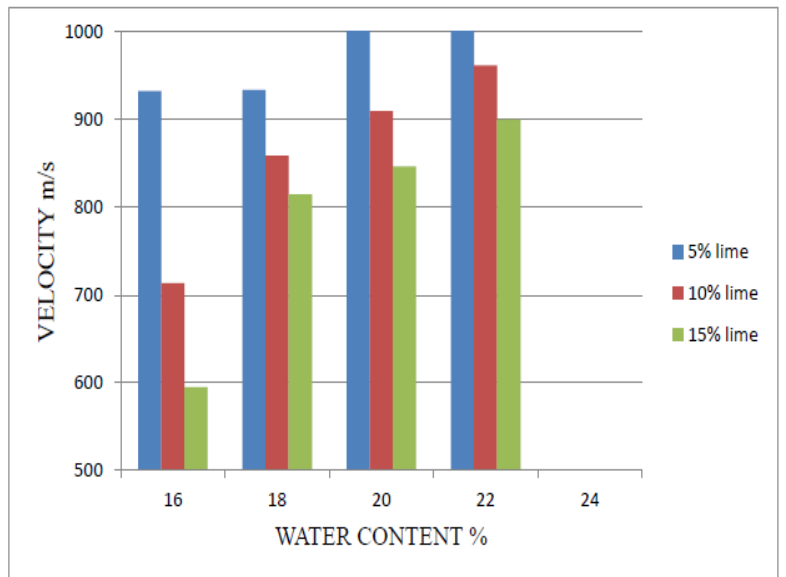

Fig. 2: Influence of Lime Content in Clay Soil on Velocity V/S Water Content.

Figure 2 represents the Velocity v/s Water content with 5\%, 10\% and $15 \%$ of lime on clay soil which indicates the variations of $p$ wave velocity with the water content by the influence of lime content in clay soil. In figure it shows that the velocity of $\mathrm{p}$-waves increases gradually with higher water content and there is no transmission of p-wave on 5\%,10\% and $15 \%$ of lime on clay soil.

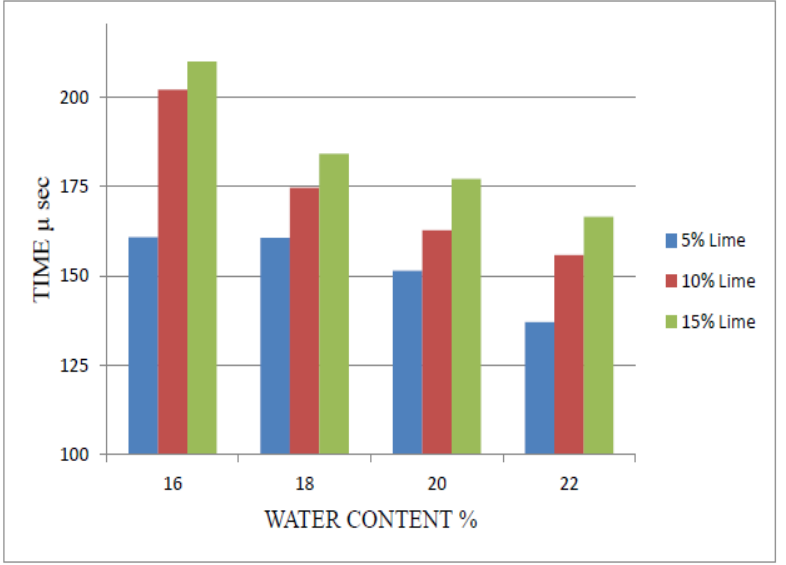

Fig. 3: Effects of Influence of Lime in Clay Soil on Time V/S Water Content.

Figure 3 represents the Time v/s Water content with 5\%,10\% and $15 \%$ of lime on clay soil which indicates the variations of time with the water content by the influence of lime content in clay soil. In figure it shows that the time of waves goes on reducing gradually with higher water content.

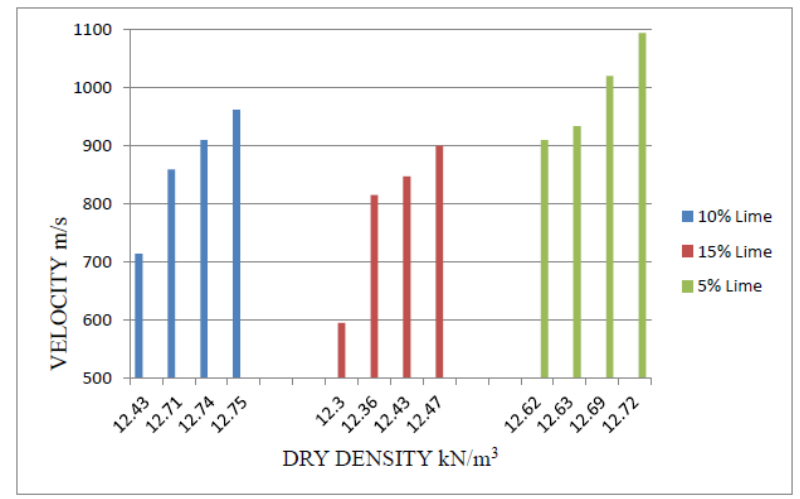

Fig. 4: Effects of Influence of Lime in Clay Soil on Velocity V/S Dry Density.

Figure 4 represents the velocity v/s Dry unit weight with 5\%, 10\% and $15 \%$ of lime on clay soil which indicates the variations in velocity and density of soil with influence of lime content in clay soil. In figure it shows that the velocity increasing with maximum density with $5 \%$ of Lime. 


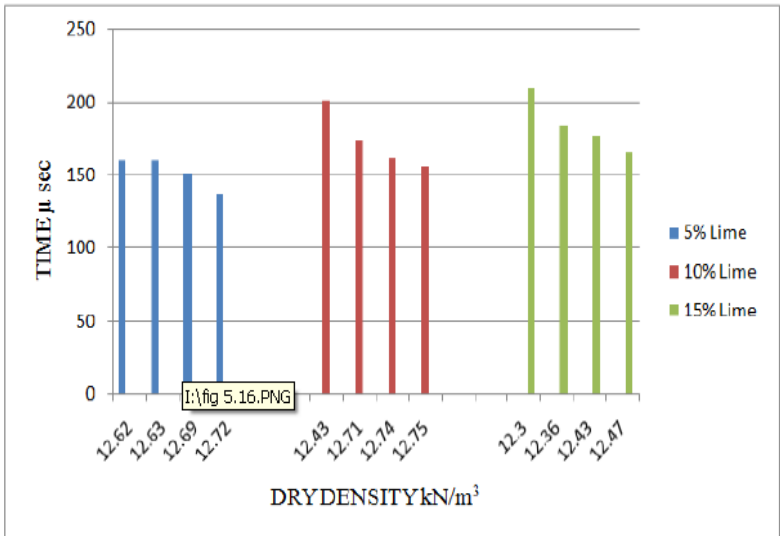

Fig. 5: Effects of Influence of Lime in Clay Soil on Time V/S Dry Density.

Figure 5 represents the Time v/s Dry unit weight with 5\%, 10\% and $15 \%$ of lime on clay soil which indicates the variations in time of p-waves and density of soil with influence of lime content in clay soil. In figure it shows that the time of waves goes on reducing gradually with decreasing density.

\subsection{For heavy compaction on lime stabilized clay soil}

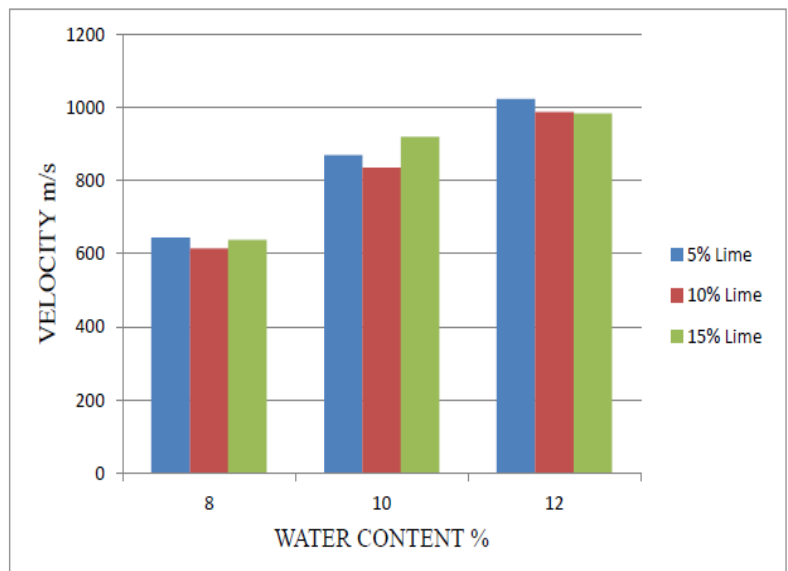

Fig. 6: Effects of Lime on Velocity V/S Water Content of the Clay Soil.

Figure 6 represents the Velocity v/s Water content with 5\%, 10\% and $15 \%$ of lime on clay soil which indicates the variations of $\mathrm{p}$ wave velocity with the water content by the influence of lime content in clay soil. In figure it shows that the velocity of p-waves increases gradually with water content. Ultrasonic waves are not transmitted in clay soil even in heavy compaction at $5 \%, 10 \%$, and $15 \%$ of lime.

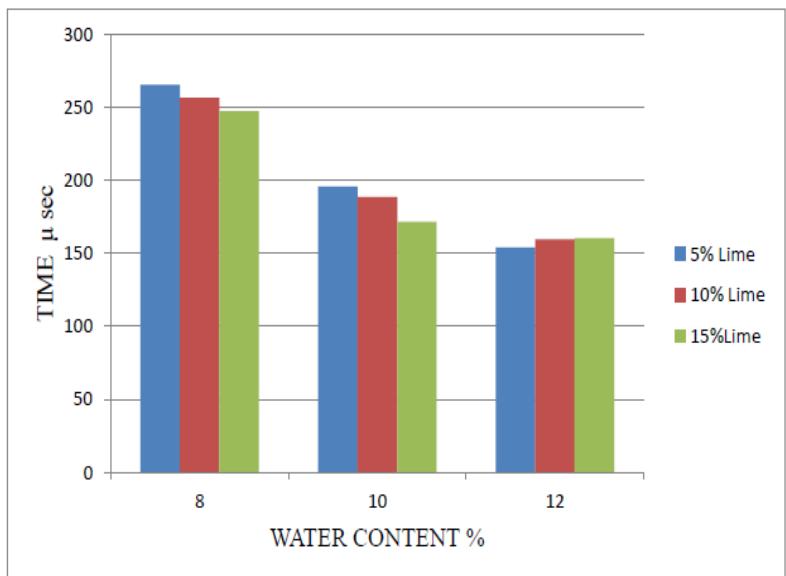

Fig. 7: Effects of Lime Influence on Time V/S Water Content of the Clay Soil Mass.
Figure 7 represents the Time v/s Water content with 5\%,10\% and $15 \%$ of lime on clay soil which indicates the variations in time with the water content by the influence of lime content in clay soil. In fig it shows that the time gets on reducing gradually with higher water content.

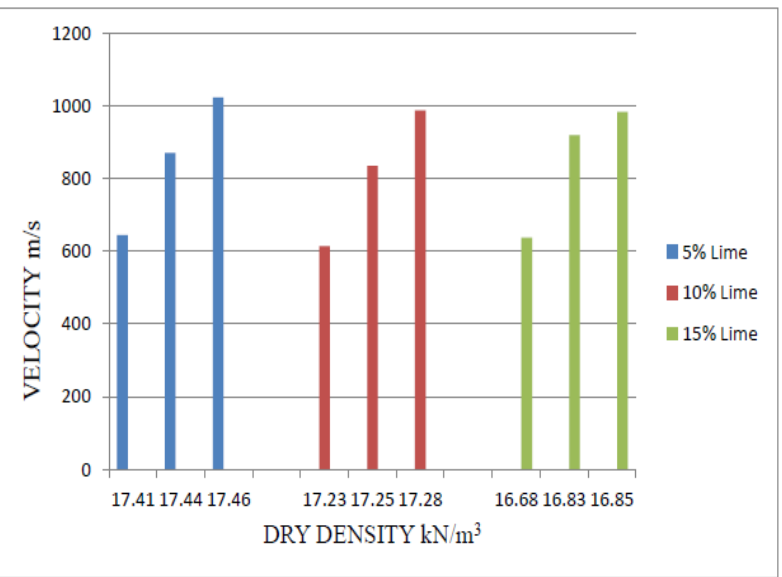

Fig. 8: Effects of the Influence of Lime on Velocity V/S Dry Density and of Lime Stabilized Clay Soil.

Figure 8 represents the Velocity v/s Density with 5\%,10\% and 15\% of lime on clay soil which indicates the variations in velocity with the density by the influence of lime content in clay soil. In figure it shows that the velocity gets on increasing gradually with varying density.

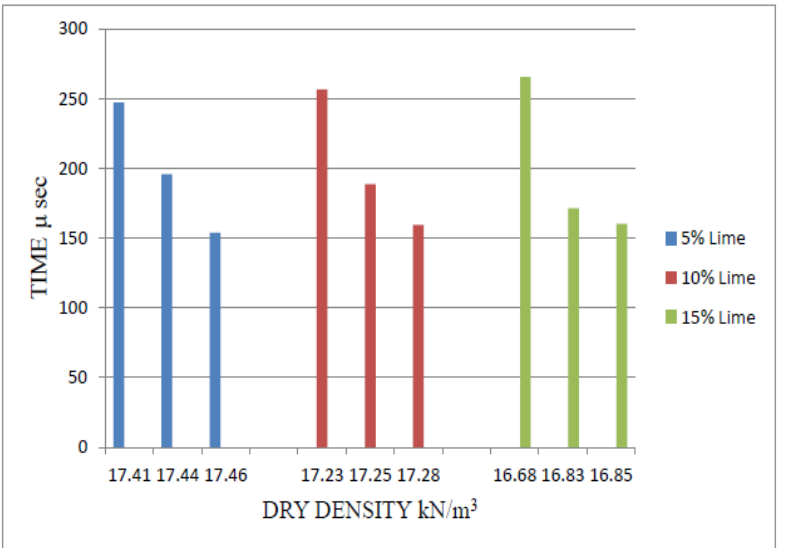

Fig. 9: Effects of Influence of Lime in Clay Soil on Time V/S Dry Density.

Figure 9 represents the Time v/s Dry unit weight with 5\%, 10\% and $15 \%$ of lime on clay soil which indicates the variations in time with the density by the influence of lime content in clay soil. In figure it shows that the time gets on reducing gradually with varying density.

\section{Conclusion}

The present investigation on application of nondestructive technique of compaction characteristics of lime stabilized soil by the means of ultrasonic measurements which provides various results and conclusions.

Following conclusions are provided in the present study

1) Due to expansiveness of clay soils and ability to swells, clay soil needs stabilization for better performance.

2) $5 \%, 10 \%, 15 \%$ lime improved the quality of the soil samples by significantly reducing their liquid limit from $59 \%$ to $49 \%, 44 \%$ and $39 \%$ respectively, plastic indices $27 \%$ to $25 \%, 22 \%, 21 \%$.

3) Lime significantly decreases the M.D.D. and O.M.C of the soil. 
4) The dry density of the lime stabilized soil increases at addition of $5 \%$ lime content and at further addition of lime at $10 \%$ and $15 \%$ the dry unit weight reduces gradually.

5) Utilization of ultrasonic method for determination of compaction characteristics proves to be fast and can be operation of ultrasonic equipment can be done with ease.

6) Nondestructive method using ultrasonic test provides effective results to determine the properties of compacted soil. The ultrasonic tests may also be utilized additional method of soil testing.

7) The variation in both velocity and density with moisture content was identical. The velocity gradually reduced with increase in the addition of lime in soil and also velocities decreased with decreasing dry unit weight.

8) The ultrasonic measuring techniques can be utilized where the destructive test are not feasible to carried out and the test technique is simple can be carried out without damaging the structures.

\section{Acknowledgement}

The Authors express their thanks to the students for the help during the conduction of Laboratory work and analysis of data. The Authors also express thanks to the Principal of the college and Head of the Department of Civil Engineering for the encouragement.

\section{References}

[1] ASTM, (1992). ASTM Standards on soil stabilization with admixtures, ASTM, West Conshohocken, PA

[2] ASTM D 4318-95a. Standard test methods for liquid limit, plastic limit and plasticity index of soil. Annual Book of ASTM Standards, vol. 4, no.8, PA: ASTM International, West Conshohocken; 1997. p 519-29.

[3] ASTM D 698-91. Test methods for laboratory compaction characteristics of soil using standard effort. Annual Book of ASTM Standards, vol. 4, no. 8, PA: ASTM International, West Conshohocken; 1997. p. 77-84.

[4] BSI (1990a) British Standard Methods of Test for Engineering Purposes: Classification Tests. British Standards Institution, Milton Keynes, BS 1377: Part 2.

[5] BSI (1990b) British Standard Methods of Test for Engineering Purposes: Compaction-Related Tests. British Standards Institution, Milton Keynes, BS 1377: Part 4.

[6] IS-2720(Part-2)-1980 Methods of test for soil Determination of Water Content.

[7] IS-2720(Part-5)-1980 Methods of test for soil Determination of Liquid and Plastic Limit.

[8] IS-2720(Part-16)-1980 Methods of test for soil Laboratory Determination of Free Swell Index of Soils.

[9] IS-2720(Part-8)-1980 Methods of test for soil Determination of Water content-Dry Density Relation using Heavy compaction.

[10] Nazli, Yesiller. GokhanInd and Carol J. Miller., "Ultrasonic Testing for Compacted Clayey Soils"

[11] Nazli Yesiller, James L. Hanson, and Mumtaz A. Usmen "Ultrasonic Assessment of Stabilized Soils"

[12] Nadagouda, K. A hegde R.A., "The Effect of Lime Stabilization on Properties of Black Cotton Soil", Indian Geotechnical Conference 2010, GEO trends December 16-18, 2010 IGS Mumbai Chapter \& IIT Bombay.

[13] Yesiller, N., Inci, G., and Miller, C. J., (2000), "Ultrasonic testing for compacted clayey soils," Advances in Unsaturated Geotechnics, ASCE GSP 99, C. D. Shackelford, S. L. Houston, and N.-Y. Chang, Eds., ASCE, 54-68. https://doi.org/10.1061/40510(287)5. 